\title{
Improving heat aging and mechanical properties of fluoroelastomer using carbon nanotubes
}

\author{
Javad Heidarian ${ }^{1,2 *}$, Aziz Hassan ${ }^{1}$ \\ ${ }^{1}$ University of Malaya, Polymer and Composite Materials Research Laboratory, Department of Chemistry, 50603, Kuala \\ Lumpur, Malaysia \\ ${ }^{2}$ Nanotechnology Research Center, Research Institute of Petroleum Industry(RIPI)-West side of Azadi Complex-Tehran- \\ -Iran, 1485733111 \\ "Corresponding author: e-mail: heidarianj@um.edu.my, heidarianj@yahoo.com
}

\begin{abstract}
Carbon nanotube (CNT)-, carbon black (CB)-filled fluoroelastomer (FE) and unfilled-FE compounds were prepared $(\mathrm{CNT} / \mathrm{FE}, \mathrm{CB} / \mathrm{FE}$ and $\mathrm{FE})$. The compounds were subjected to heat air aging and characterized by tensile test and X-Ray Diffraction (XRD) analysis. Results show that CNT improved tensile properties of FE before and after aging. All samples show stress induced crystallization (SIC) during tension. XRD results show that under all conditions, the crystals were in the form of $\gamma$-phase. For both aged and un-aged specimens, the degree of crystallinity $\left(X_{c}\right)$ is low. After tensile stretching, $X_{c}$ of un-aged specimens increases tremendously, with larger crystal size. Under the same conditions, the order of elongation at break (EL) was FE $>\mathrm{CB} / \mathrm{FE}>\mathrm{CNT} / \mathrm{FE}$. Normal modulus (NM) and tangent modulus (TM) at the same conditions was in the order of CNT/FE > CB/FE > FE. Tensile strength had the order of $\mathrm{CNT} / \mathrm{FE}>\mathrm{CB} / \mathrm{FE}>\mathrm{FE}$.
\end{abstract}

Keywords: fluoroelastomers, crystallization, tension test, X-ray diffraction topography, aging.

\section{INTRODUCTION}

Carbon nanotubes (CNT) can improve many properties of fluoroelastomers (FE) for different applications especially in oil and gas industries ${ }^{1-3}$. To predict the service life of a rubber component subjected to a variety of environments, it is necessary to account for all modes of degradation. CNT is expected to improve aging and mechanical properties of FE compared to unfilled FE or carbon black $(\mathrm{CB})$ filled $\mathrm{FE}(\mathrm{CB} / \mathrm{FE})$.

Faulkner et al. $^{4}$ reported on improving tensile and tear strength and energy to break (elongational stress-strain energy to failure) in $\mathrm{CNT} / \mathrm{FE}$ nanocomposites. The authors concluded that CNT at low durometer in peroxide cure $\mathrm{FE}$ compared to $\mathrm{CB} / \mathrm{FE}$ is not effectively reinforcing. However, CNT highly reinforces FE at high durometer/stiffness. Changes in mechanical properties of CNT/FE due to heat aging were also reported.

Wang et al. ${ }^{5}$ verified the aging behavior of the reactive blends of FE and another nitrile or natural rubber. The authors used fourier transform infra-red (FTIR) spectroscopy and X-ray photoelectron spectroscopy (XPS) for the characterization. Their results showed that FE underwent thermal oxidation and hydrofluorination reaction during aging. Subsequently carboxyl group and carbon double bond were formed, and fluoro group shifted to the surface at the aging temperature of $200^{\circ} \mathrm{C}$.

A considerable depletion of fluorine $(\mathrm{F})$ and carbon (C) on the surface and to the depth of around 10-15 $\mu \mathrm{m}$ of cross-section of aged $\mathrm{CB} / \mathrm{FE}$ seals in oil containing amine based dispersant at $150^{\circ} \mathrm{C}$ was also reported by Smith et al. $^{6}$ The authors concluded that polytetrafluoroethylene (PTFE) begins to soften and release $\mathrm{F}$ at around $200-220^{\circ} \mathrm{C}$. This may explain the apparent susceptibility to heating in air shown by elastomer with high tetra-fluoroethylene (TFE) content.

Change in crystallinity of filled fluoropolymers under shear is reported by many researchers ${ }^{7-9}$. Chae and Hong ${ }^{10}$ reported that in the dynamic crystallization under shear, MWCNTs have a nucleating effect on the PVDF, reducing both induction and crystallization times with increasing MWCNT contents. The same phenomenon for PVDF-nanoclay composites was reported by Yang et al. ${ }^{11}$. According to this study, shear field and organophilic montmorillonite (OMMT) nanoclay synergistically promote the formation of polar crystalline phase ( $\beta$ - or $\gamma$-crystalline phase with trans-conformers) in PVDF. On the other hand, it was reported that external force fields, such as ultrasonication ${ }^{12}$, uniaxial stretching and electric field (electrospinning $)^{13-15}$, are helpful for overcoming the energy barrier of molecular chain configuration, thus facilitating the formation of polar crystalline phase in PVDF.

Effects of CNT on improving tensile properties of $\mathrm{FE}$ before and during heat air aging are seldom verified by researchers. As such, comparisons of tensile properties of $\mathrm{CNT} / \mathrm{FE}$ with $\mathrm{CB} / \mathrm{FE}$ and $\mathrm{FE}$ in the above conditions are yet to be carried out. FE, $\mathrm{CB} / \mathrm{FE}$ and $\mathrm{CNT} / \mathrm{FE}$ specimens were subjected to the degree of crystallinity characterization by XRD analysis. Comparisons were made between before and after aging (original compound) and before and after tensile test of un-aged, tensile fractured specimens. Comparisons between the tensile tested aged- and un-aged specimens were also made. Analyses in these aspects are rather novel, specifically verifying the possible stress induced crystallization (SIC) in the tensile tested samples. These findings will show the possible potential of CNT in improving tensile properties and aging resistance of $\mathrm{CNT} / \mathrm{FE}$ compared to $\mathrm{CB} / \mathrm{FE}$ and FE. This improvement of crystallinity consequently will improve tensile properties of CNT/FE compared to $\mathrm{CB} / \mathrm{FE}$ and $\mathrm{FE}$.

\section{EXPERIMENTAL}

\section{Material}

Materials used were Viton GF-600S fluoroelastomer, FE, a terpolymer of hexafluoro-propylene (HFP), vinyli- 
dene fluoride (VDF), and TFE with a cure site monomer; organic peroxide, Luperox 101 XL-45; carbon nanotube, CNT (TNM8, outside diameter $>50 \mathrm{~nm}$, purity $>95 \%$, and length of 10-20 $\mu \mathrm{m}$ ); carbon black, CB Ensaco 250; and triallylisocyanurate, TAIC supplied by ERIKS Sdn. Bhd. (Malaysia), Arkema Sdn. Bhd. (Malaysia), Chengdu Organic Chemicals Co. Ltd. (Chinese Academy of Sciences, China), Age D'Or Industrial Sdn. Bhd. (Malaysia) and Liu Yang San Ji Chemical Trade Co. Ltd. (China) respectively. Three formulations were compounded; CNT filled FE (CNT/FE), CB filled FE (CB/FE) and unfilled $\mathrm{FE}$ (FE). In all compounds, the amount of FE, organic peroxide and TAIC were 70.0, 2.1 and 2.1 $\mathrm{g}$ respectively. For CNT/FE and $\mathrm{CB} / \mathrm{FE}, 7.0 \mathrm{~g}$ of CNT and $\mathrm{CB}$ respectively, were added.

\section{Compounding}

Mixing FE with additives was done using a laboratory scale two roll mill with a roll temperature of $48^{\circ} \mathrm{C}$. $\mathrm{FE}$ in the above mentioned composition was supplied to open roll. A uniform band was formed while three rolling cuts from each side of the mill were made, so that the polymer becomes homogenous and sufficiently warm up. Then TAIC was added uniformly into the gum and three rolling cuts from each side of the mill were done. After setting the roll distance to $1.1 \mathrm{~mm}, \mathrm{CNT}$ was then fed in. The compound was then tight milled ten times. The roll distance was then adjusted to $1.1 \mathrm{~mm}$, and peroxide was added. Once the final 5 to 6 rolled up end passes, the mixture was supplied to the open roll and sheeted. After 24 hours, re-milling was done with a roll temperature of $26^{\circ} \mathrm{C}$. The same procedure was used for $\mathrm{CB} / \mathrm{FE}$ and $\mathrm{FE}$.

\section{Curing and post curing}

Curing of FE compound was done with the mold $(18 \mathrm{~cm} \times 18 \mathrm{~cm} \times 2 \mathrm{~mm})$ in a heated press, at $177^{\circ} \mathrm{C}$ under pressure of $10 \mathrm{MPa}$ for $7 \mathrm{~min}$. The post curing was done in air oven at $232^{\circ} \mathrm{C}$ for 2 hours. Conditions for curing and post curing were recommended by the supplier.

\section{Thermal aging}

Thermal aging was done according to ASTM D-573 standard for 24,48 and 72 hours at $250^{\circ} \mathrm{C}$. The samples were named FE, FE-24, FE-48 and FE-72, where the numbers following, FE indicates the aging time in hours. Similar styles of abbreviations were used for $\mathrm{CB} / \mathrm{FE}$ and $\mathrm{CNT} / \mathrm{FE}$ aged samples.

\section{Characterization}

Tensile test The dumb-bell shaped specimens were cut from the molded post-cured rubber sheet using Wallace (UK) type C die cutter. Tensile properties were determined according to ASTM D-412 standard at room temperature using universal testing machine, Instron 3345 (USA) with load-cell of $5 \mathrm{kN}$ and the cross-head speed of $500 \mathrm{~mm} \mathrm{~min}^{-1}$. Minimum of six specimens were tested and the data reported is the average of at least four reproducible results.

X-Ray Diffraction (XRD) Un-aged and aged samples of $1.5 \mathrm{~cm} \times 1.5 \mathrm{~cm} \times 2.0 \mathrm{~mm}$ dimensions from the molded post cured $\mathrm{FE}, \mathrm{CB} / \mathrm{FE}$ and $\mathrm{CNT} / \mathrm{FE}$ rubber sheets were used for XRD analyses. The fractured tensile specimens of aged and un-aged samples were also characterized. For these tests, samples were cut from the near broken area of the dumb-bell specimens. The samples were named with additional ' $\mathrm{T}$ ' at the end of original name, for instance FE-72T, in which $\mathrm{T}$ indicates that the sample was taken from the broken specimen of tensile test. The same abbreviations were used for other samples. XRD spectrometer, PANalytical Empyrean Model DY1032 was used for the characterization at $2 \theta$ of $5^{\circ}$ to $80^{\circ}$.

\section{RESULTS AND DISCUSSION}

\section{Tensile properties}

Figure 1 (a) shows the selected stress-strain curves for un-aged and 72 hours aged FE composites. Their properties are discussed individually below.

Tensile strength Figure 1 (b) shows the tensile strength (TS) of FE composites at different aging times, extracted from the stress-strain curves. As can be seen from this figure, TS of $\mathrm{FE}$ and $\mathrm{CB} / \mathrm{FE}$ decrease with increasing aging time (except during the first 24 hours). However, for CNT/FE; TS has negligible decreases with increasing aging time (except during the first 24 hours). In CNT/ FE, most degradation happened during the first 24 hours and not much change after that. However, for $\mathrm{CB} / \mathrm{FE}$ and FE degradation continued until 72 hours. This is due to better degradation resistance of CNT.

TS of FE and CB/FE increases after 24 hours of aging compared to un-aged $\mathrm{FE}$ and $\mathrm{CB} / \mathrm{FE}$ respectively (probably due to increase in cross-linking).

Elongation at break (EB) Figure 1 (c) shows the elongation at break (EB) of FE composites at different aging times. Normally, the change in EB due to aging is a criterion of degradation, therefore less change in $\mathrm{EB}$ show less effect of aging. As can be seen in this figure, $\mathrm{EB}$ for $\mathrm{FE}$ and $\mathrm{CB} / \mathrm{FE}$ increases with increasing aging time during the first 24 hours however, with further increasing the aging time the changes in EB are negligible. In comparison to CNT/FE, EB of CNT/FE-24 decreases slightly after 24 hours of aging. However, after 48 hours, EB increases while until 72 hours it is almost constant. This behavior proves that most of CNT/FE degradation happened during the first 48 hours.

Comparing tensile strength and elongation at break of un-aged specimens As can be seen in Figure $1(\mathrm{a}-\mathrm{c})$, among all samples, FE has the highest EB and the lowest $\mathrm{TS}$, and $\mathrm{CNT} / \mathrm{FE}$ has the highest TS and lowest EB, while $\mathrm{CB} / \mathrm{FE}$ has intermediate $\mathrm{EB}$ and TS. However, in comparing $\mathrm{CNT} / \mathrm{FE}$ and $\mathrm{CB} / \mathrm{FE}$ curves, it shows that $\mathrm{CNT}$ improves TS and increases EB. This is because CNT is nanofiller which have more surface area compared to normal filler of CB. More surface area will cause more interaction between CNT and FE compared to $\mathrm{CB}$ and FE. Thus, it causes more physical and chemical contact resulting in more cross-linking points and less free volu$\mathrm{me}^{1,16,17}$. Therefore, CNT/FE has higher TS and lower EB. Pham et al. ${ }^{16}$ also studied the effect of increasing CNT loadings on the mechanical properties such as tensile strength, tensile modulus, elongation at break, hardness and tear resistance. The authors concluded that 


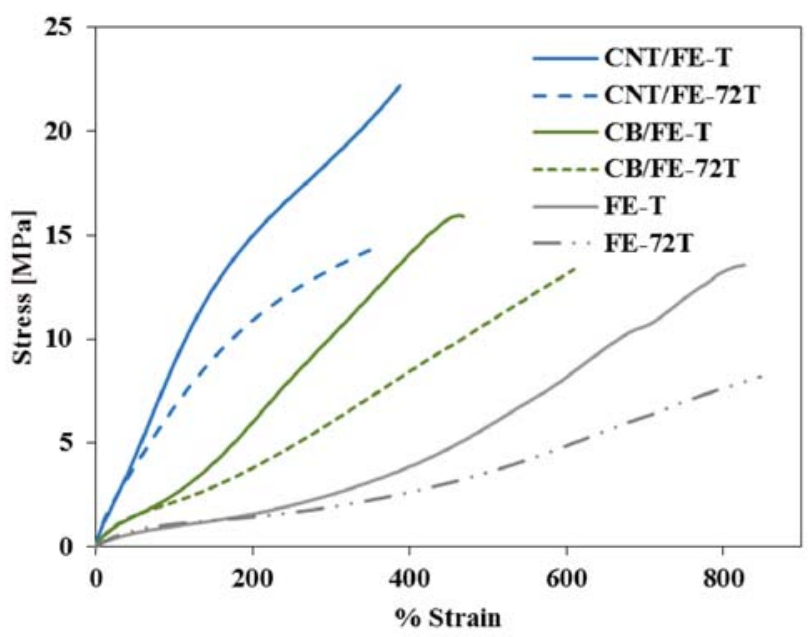

(a)

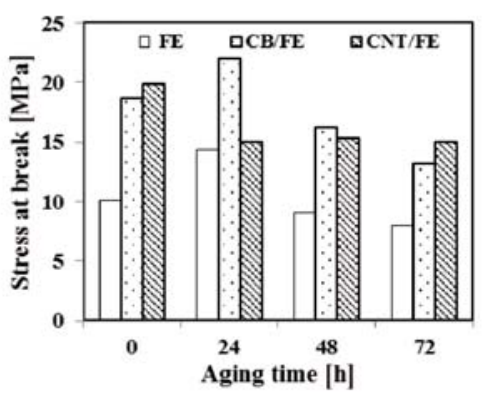

(b)

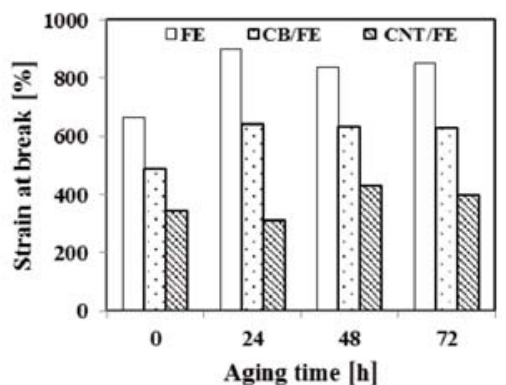

(c)

Figure 1. (a) Stress-strain curves of unaged and 72 hours aged samples, (b) Tensile strength and (c) Elongation at break at different aging times of filled and unfilled FE

a continuous increase in the performance characteristics shows the reinforcing nature of CNT in FE.

Stress induced crystallization (SIC) Figure 1 (a) also shows that FE undergo stress hardening or stress induced crystallization (SIC), that starts at about $200 \%$ strain. SIC will cause increase in modulus and strength. The SIC is very similar to necking phenomenon in polymer. The same phenomenon can be seen in $\mathrm{CB} / \mathrm{FE}$ whereby SIC starting at about $100 \%$ strain. Thus in CB/FE, SIC starts from lower strain. This is due to having less necking strain domain in the case of $\mathrm{CB} / \mathrm{FE}$, caused by the interaction between filler and $\mathrm{FE}$ which resulted in more physical and chemical bonds acting as cross-linking points for FE. These cross-linking points inhibit the chains of polymers from slipping and therefore resulting in shorter strain range in which crystallization happened. Upon stretching, $\gamma$-phase of VDF crystals is formed. Producing $\gamma$-phase in VDF segments needs a high shear which can be obtained upon using high $\operatorname{strain}^{10}$.

For CNT/FE, SIC appeared at $50 \%$ strain. This is again due to more cross-linking points between CNT and $\mathrm{FE}$ with less free volume compared to $\mathrm{CB} / \mathrm{FE}$ as explained previously. Figure 1 (a) also shows that the tangent modulus of $\mathrm{FE}$ and $\mathrm{CB} / \mathrm{FE}$ increases with increasing strain. On the other hand, tangent modulus of CNT/FE at strains above $100 \%$ decreases with an increase in strain.

Figure 1 (a) also shows that, SIC for 72 hours aged $\mathrm{FE}$ and $\mathrm{CB} / \mathrm{FE}$ started at the same strain as the un-aged samples. This clearly indicates that aging does not affect the SIC initiation in FE and $\mathrm{CB} / \mathrm{FE}$.

Tangent modulus Figure $2(\mathrm{a}-\mathrm{c})$ show the tangent modulus versus strain of unfilled and filled FE at different aging times. As can be seen in Figure 2 (a), for $\mathrm{FE}$ and aged $\mathrm{FE}$ the tangent modulus decreases from $0 \%$ to $200 \%$ strain and at strains higher than $200 \%$ it increases with increasing strain. This explains that in FE and aged FE, the SIC starts from $200 \%$ strain. This FE containing VDF and TFE segments are capable of producing crystals particularly under shear fields ${ }^{10,18}$. Figure 2 (b) indicates that for both aged and un-aged $\mathrm{CB} / \mathrm{FE}$, the minimum tangent modulus appears at around $100 \%$ strain (SIC starting point). In comparison, SIC of aged and un-aged $\mathrm{CB} / \mathrm{FE}$ and $\mathrm{FE}$ reached at much lower strains.

Figure 2 (c) shows that for CNT/FE, a minimum tangent modulus at around $50 \%$ strain in the strain range of $0-100 \%$ and at strains higher than $100 \%$, there is a continuous decrease in modulus. The continuous decrease in tangent modulus happens (occurs) when deformation (strain) is increased, because some of the physical cross-linking may dissipate as polymer chain slides over the nanotube resulting in the deterioration of properties. The similar deterioration in properties with deformation was explained for CNT-natural rubber nanocomposites ${ }^{17}$.

As can be seen from Figure $2(\mathrm{a}-\mathrm{c})$, at each fixed strain the modulus of unfilled and filled -FE decreases 
(a)

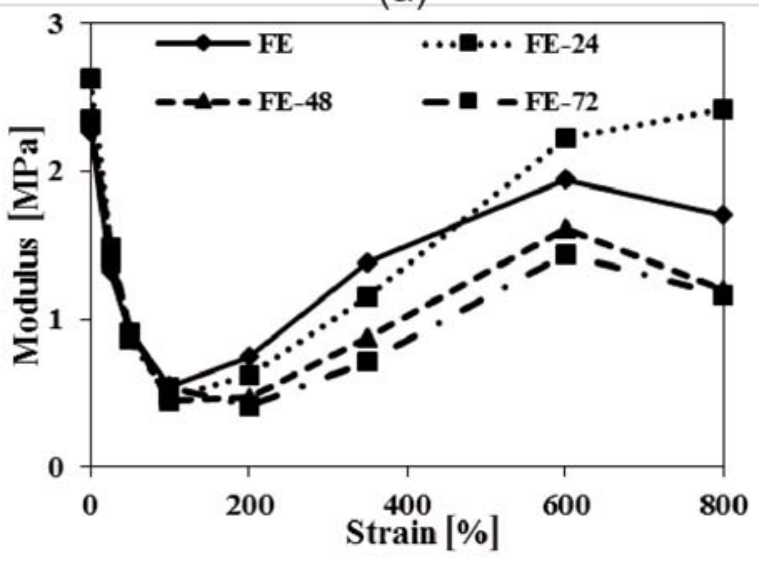

(b)

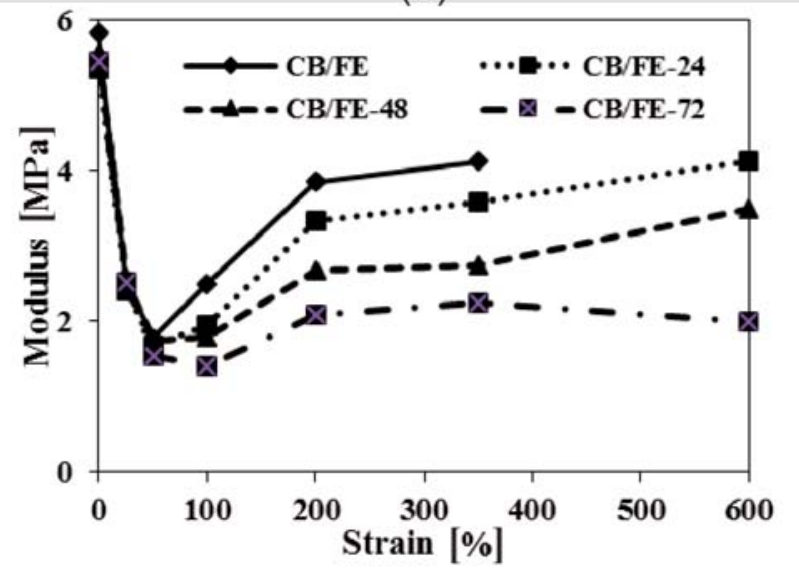

(c)

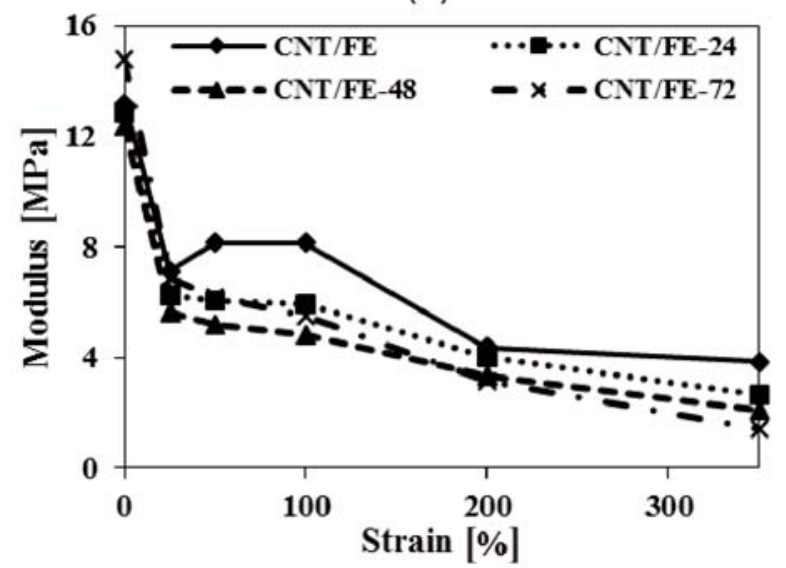

Figure 2. Tangent modulus versus strain of: (a) FE, (b) $\mathrm{CB} / \mathrm{FE}$ and (c) CNT/FE at different aging times

with increasing aging time. This is due to the increasing degradation and reducing crystallinity of them after aging. Figure 2 (c) also shows that for CNT/FE, the most significant change in tangent modulus at each fixed strain is during the first 24 hours of aging.

Higher shear due to the presence of CNT and more physical and chemical cross-links between CNT and FE causes SIC to appear at lower strains compared to $\mathrm{CB} / \mathrm{FE}$ and FE. The same reasons can be attributed for SIC in $\mathrm{CB} / \mathrm{FE}$ starting at lower strains compared to that of FE.

Figure 3 shows the tangent modulus ratio (TMR) of FE composites at different aging times, defined as,

$\mathrm{TMR}_{\mathrm{s} 1, \mathrm{~s} 2}=\frac{\mathrm{TM}_{\mathrm{s} 1}}{\mathrm{TM}_{\mathrm{s} 2}}$

where, $\mathrm{TM}_{\varepsilon 1}$ and $\mathrm{TM}_{\varepsilon 2}$ are the tangent moduli at strains 1 and 2 respectively.

The above ratio is obtained by dividing tangent modulus at a strain after SIC has started $\left(\mathrm{TM}_{\varepsilon 1}\right)$ by the tangent modulus at a strain before $\left(\mathrm{TM}_{\varepsilon 2}\right)$. These ratios were obtained in order to see how SIC improve the tensile properties. For FE, for example $\mathrm{TM}_{600,100}$ was used, for $\mathrm{CB} / \mathrm{FE}, \mathrm{TM}_{350,50}$ and for $\mathrm{CNT} / \mathrm{FE}, \mathrm{TM}_{100,25}$ and $\mathrm{TM}_{350,250}$ were chosen. As shown in Figure 3, the ratios are greater than 1, indicating high SIC. The ratio larger than 1 (horizontal line at TMR $=1$ ) shows increase in modulus and indicates SIC. The TMR for CNT/FE is almost 1. This is because the tangent moduli of CNT/FE before SIC are already high and SIC slightly improves the tangent modulus. The ratios have the following order for different fillers at each aging time: $\mathrm{FE}>\mathrm{CB} / \mathrm{FE}>$ CNT/FE. This shows more improvement in the moduli of FE under shear compared to the others.

Figure 3 also shows that for all samples, the ratio reduces with increasing aging time. This is because of decrease in percentage of crystallinity due to degradation, dehydrofluorination and carbon oxygen reactions, particularly at and near the surface ${ }^{5}$, therefore reducing the modulus of elasticity.

Normal modulus Figure 4 shows the normal modulus (NM) of FE composites at different aging times and strains. NM is the stress obtained from tensile stress-strain curves at a fixed strain. For example, NM100 is the stress at $100 \%$ strain of tensile test curve. The results in Figure 4 shows that at each fixed strain, NM decreases in the order of $\mathrm{CNT} / \mathrm{FE}>\mathrm{CB} / \mathrm{FE}>\mathrm{FE}$. The reasons for improvement in tensile properties in the above order are the same reasons as explained for the TS. Results indicate that NM mostly decreases with increasing aging time especially at higher strains; however, there was no fixed trend at lower strains. The reasons for the decrease in NM with aging time are the same as explained for TM reduction with aging time.

At high strains, the effect of degradation is significant because of shorter polymer chains in the aged samples. It is due to thermal and oxidative degradation as well as low percentage of crystallinity in them as explained before. 


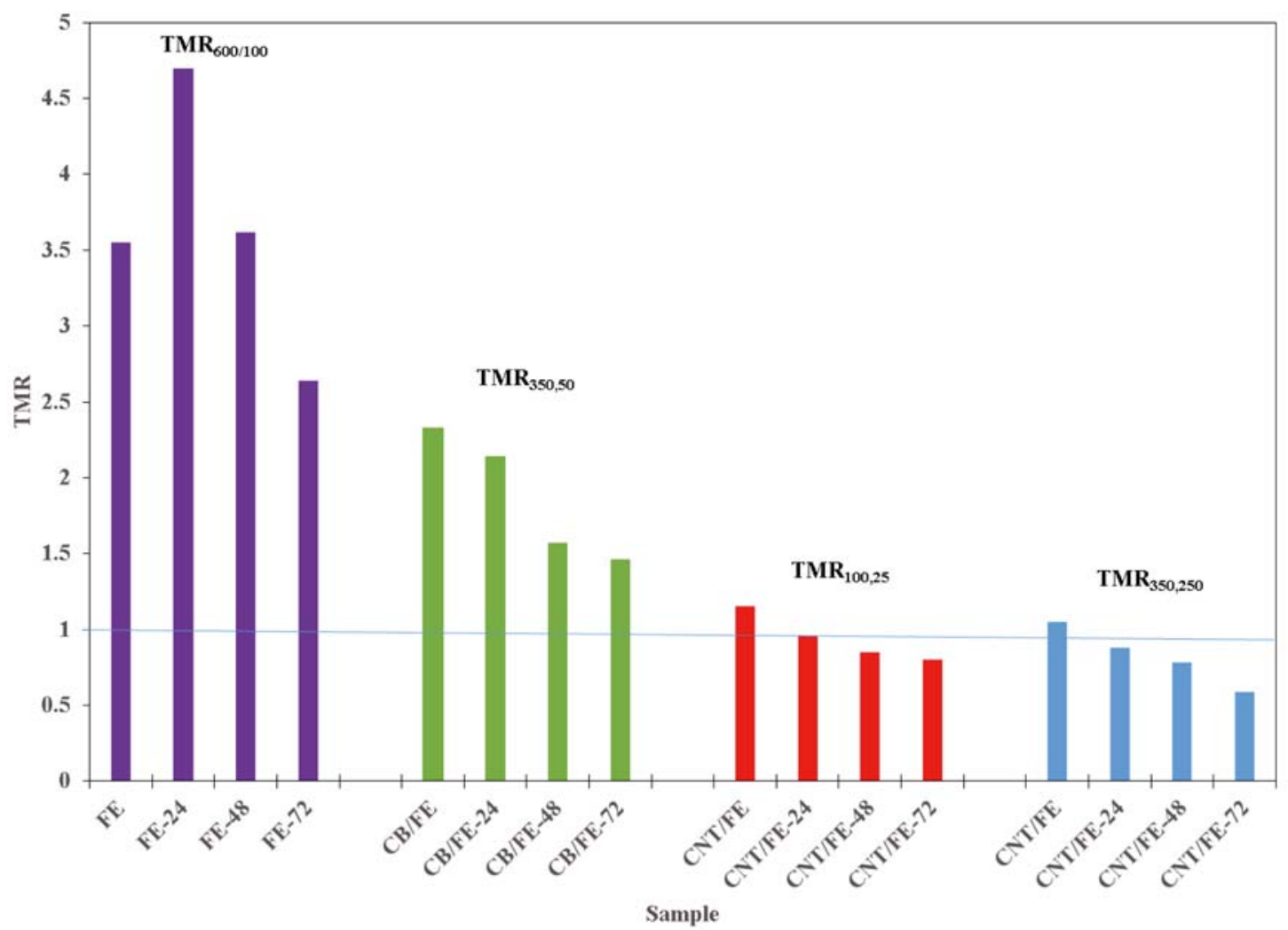

Figure 3. Tangent modulus ratio (TMR) of filled- and unfilled-FE at different aging times

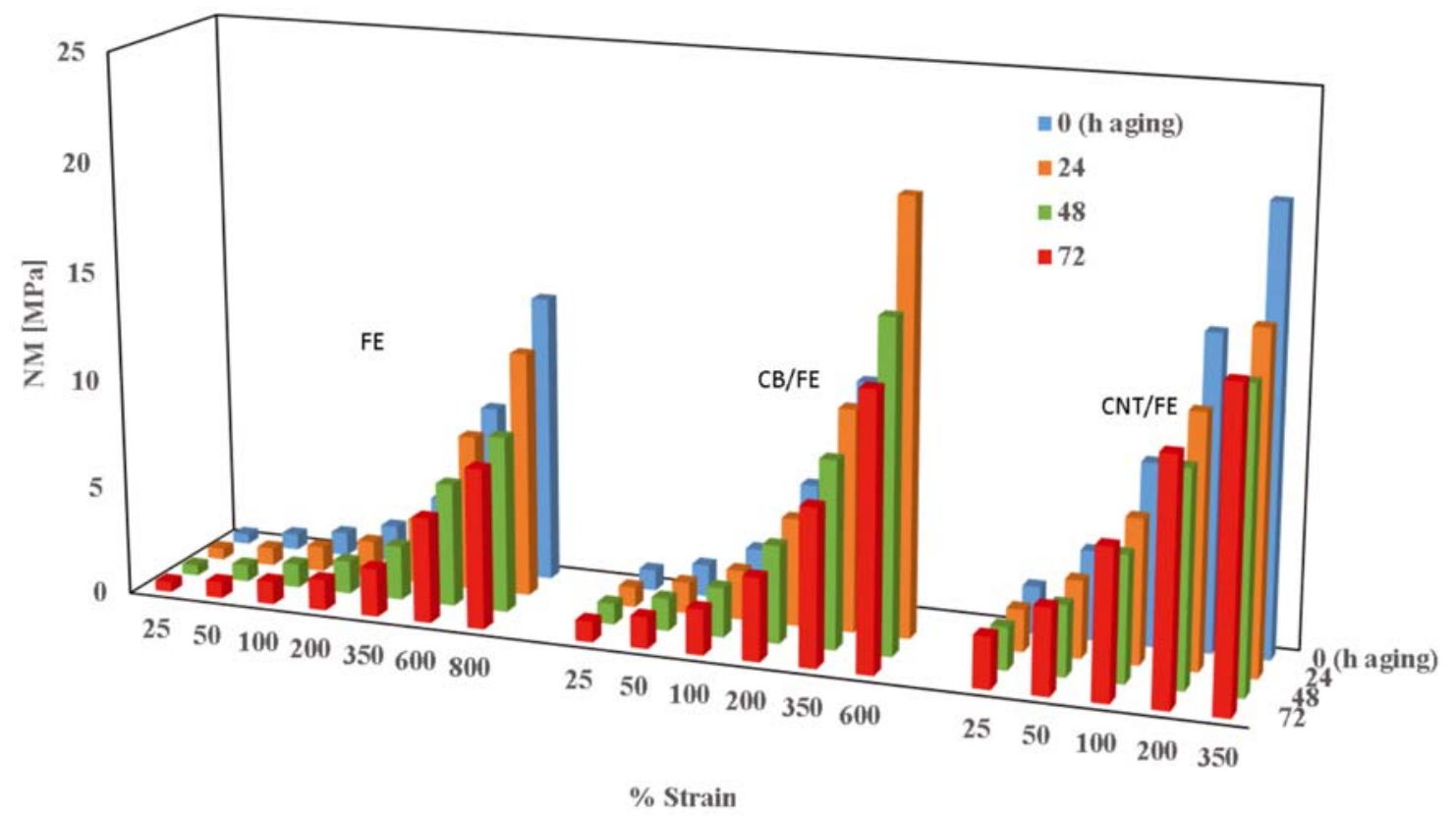

Figure 4. Normal modulus (NM) of filled- and unfilled-FE at different aging times and strains

For $\mathrm{CB} / \mathrm{FE}$ composites, at lower strains the $\mathrm{NM}$ is almost constant. This indicates that $\mathrm{CB}$ can prevent degradation at low deformations. This is because under low strain, the physical cross-links between filler and FE is not dissipated. Under low deformation, filler is also the major component contributing to the composite properties. Bonded rubber to filler is also a contributing factor by increasing effective filler amount, resulting in reducing degradation.

For CNT/FE (Fig. 4), the same trend as CB/FE sample is observed. There is more dissipation of physical cross-linking between $\mathrm{CNT}$ and $\mathrm{FE}$ at high deformations compared to $\mathrm{CB}$ and $\mathrm{FE}$, resulting in more drops in NM. The reasons are the same as explained for TM.

Totally it can be concluded that CNT improved tensile properties of FE before and after aging. CNT can prevent degradation of FE for several reasons. Firstly, the presence of CNT in FE makes the active centers of FE main chains inactive, preventing the degradation, therefore can preserve FE nearer to the CNT surface. Secondly, the interaction between CNT and FE results in increased physical and chemical cross-linking points 
which prevent the degradation of the polymer chains. Considering that the degradation of FE is a radical chain reaction, it is therefore susceptible to inhibition by reagents capable of trapping such radicals. Furthermore, the antioxidant nature of CNT, attributed to its high electron affinity $(\approx 2.65 \mathrm{eV})$, enables it to act as a radical scavenger. Consequently, CNT helps to trap radicals and inhibiting degradation of FE nearer to it. A similar reason has been given for increased decomposition temperature caused by using CNT in $\mathrm{FE}^{\mathbf{1 6}}$. Moreover, Endo et al. ${ }^{1}$, reasoned that thermal stability of FE near CNT is due to the presence of bounded rubber to CNT and concluded that this structure can prevent the decomposition of rubber at high temperatures by resisting the molecular mobility.

\section{XRD}

XRD of FE Figure 5 shows XRD spectra of FE and FE-72 before and after tensile test. The figure shows that for FE, there is a sharp peak at $2 \theta=29.45^{\circ}$ and some small peaks at $36.08^{\circ}, 39.47^{\circ}, 41.05^{\circ}$ and $43.16^{\circ}$. All of these peaks belonged to $\gamma$-phase of VDF segments ${ }^{18-23}$. Particularly the peak at $29.45^{\circ}$ belongs only to $\gamma$-phase ${ }^{23}$. Because the intensity of these peaks except the one at $29.45^{\circ}$ is very low, therefore $\mathrm{FE}$ is only slightly crystalline. Table 1 shows the relative intensity, height, full width at half maximum (FWHM) and tip width of each peak for FE. The relative intensity is the ratio of the peak intensity to that of the most intense peak. Relative intensity can be used for comparing intensity of peaks to each other in one sample and to the similar peaks at another sample. Height of the peak is directly related to the peak intensity. FWHM is inversely related to the crystallite size. The tip width is the width, where the second derivative is less than zero. The smaller the FWHM value and tip width, the more homogeneous the grids and the more orderly arrangement of crystals are.

However, in the same figure for FE-T, it can be seen that almost the same peaks (having nearly the same intensity) as that of FE appeared. However, two new peaks at $14.46^{\circ}$ and $28.72^{\circ}$ appeared, again showing $\gamma$-phase crystallinity $^{19}$ of FE-T with slightly more crystallinity compared to FE. Table 1 also shows the peak list for FE-T. The peaks at $5.96^{\circ}$ and $16.63^{\circ}$ for $\mathrm{FE}$ and $6.64^{\circ}$ and $16.73^{\circ}$ for FE-T respectively contains amorphous hollows of FE and FE-T ${ }^{24}$. In FE-T, due to increasing crystallinity, the intensity of these two peaks decrease compared to that of FE respectively.

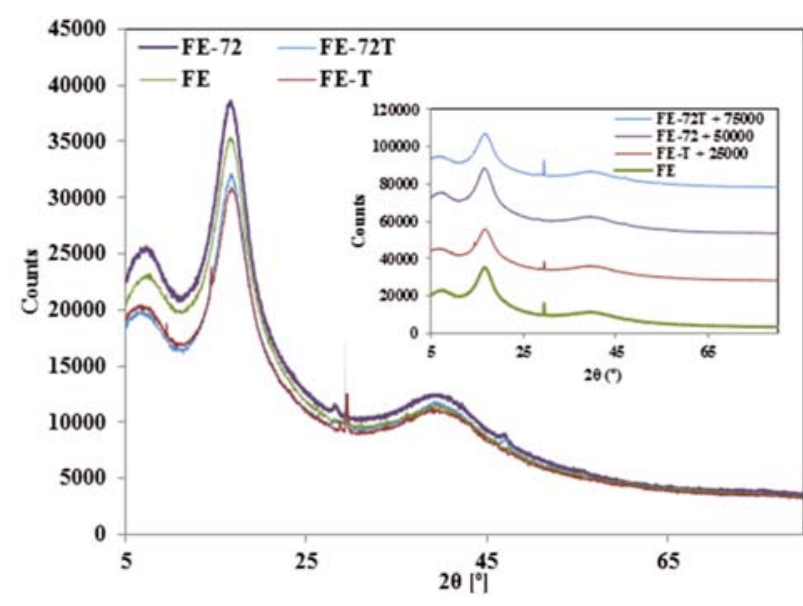

Figure 5. An XRD spectra of FE and FE-72 before and after tensile test (overlaid and separated)

The relative intensity in Table 1 is the intensity ratio of each peak to the amorphous peak at $16.63^{\circ}$ for FE and FE-T. Therefore, increase in relative intensity of each common crystal peaks in FE-T compared to that of $\mathrm{FE}$ in that table shows that the crystallinity increases in FE-T. The reasons being, the intensity of crystalline peak increased and the amorphous peak intensity decreased as mentioned before, therefore the ratio of them (relative intensity) increased. As a result, the increase in relative intensity can be a criterion for comparing crystallinity between different samples. For the common peaks of FE and FE-T, FWHM and tip width also increased or remained unchanged. However, for new peaks in FE-T, FWHM and tip width are low, indicating that the size and order of crystals is high in FE-T. The above results and having new peaks in FE-T compared to FE shows that after tensile test, crystallinity increase due to SIC. These results also confirm the tensile results that showed SIC during tensile test for FE.

Figure 5 also shows that in FE-72, there are some main peaks at $28.17^{\circ}, 39.35^{\circ}, 39.26^{\circ}$ and $46.66^{\circ}$ and some small peaks at $42.12^{\circ}$ and $55.52^{\circ}$. Once again, all of these peaks show $\gamma$-phase crystallinity of VDF segments in $\mathrm{FE}^{\mathbf{1 9}, 20}$, especially the peaks at $28.17^{\circ}$ and $46.66^{\circ}$. The intensity of these two peaks are moderate, therefore the FE-72 is partially crystalline. Table 2 shows the peak list for FE-72 and FE-72T. Comparing FE and FE-72 in this table, it shows that the peaks increased in intensity especially at $28.17^{\circ}$ and $46.66^{\circ}$. This shows that due to aging at high temperature, $\gamma$-phase crystallinity increase. As mentioned by Chae and $\mathrm{Hong}^{\mathbf{1 0}}$, at temperatures above $155^{\circ} \mathrm{C}$, there is increasing $\gamma$-phase crystallinity.

Table 1. XRD peak list of FE and FE-T

\begin{tabular}{|c|c|c|c|c|c|c|c|c|c|}
\hline \multicolumn{5}{|c|}{$\mathrm{FE}$} & \multicolumn{5}{|c|}{ FE-T } \\
\hline Pos. $\left[{ }^{\circ} 2 \theta\right]$ & Height [cts] & $\begin{array}{c}\text { FWHM } \\
\left.\text { Left [ }{ }^{\circ} 2 \theta\right]\end{array}$ & $\begin{array}{c}\text { Rel. Int. } \\
{[\%]}\end{array}$ & Tip Width & $\begin{array}{l}\text { Pos. } \\
{\left[{ }^{\circ} 2 \theta\right]}\end{array}$ & Height [cts] & $\begin{array}{c}\text { FWHM } \\
\left.\text { Left [ }{ }^{\circ} 2 \theta\right]\end{array}$ & $\begin{array}{c}\text { Rel. Int. } \\
{[\%]}\end{array}$ & Tip Width \\
\hline 5.9633 & 17580.11 & 1.2280 & 57.22 & 1.4736 & 6.6402 & 15892.81 & 1.6374 & 60.01 & 1.9649 \\
\hline 7.4599 & 18430.79 & 1.4327 & 59.99 & 1.7192 & 7.6846 & 15679.07 & 0.8187 & 59.21 & 0.9824 \\
\hline 16.6266 & 30722.26 & 1.4327 & 100.00 & 1.7192 & 9.5119 & 14460.41 & 0.0768 & 54.60 & 0.0921 \\
\hline 29.4540 & 11635.87 & 0.1023 & 37.87 & 0.1228 & 14.4596 & 19491.94 & 0.0768 & 73.60 & 0.0921 \\
\hline 36.0843 & 6220.90 & 0.3070 & 20.25 & 0.3684 & 16.7321 & 26482.39 & 1.8420 & 100.00 & 2.2105 \\
\hline 39.4710 & 6964.41 & 0.6140 & 22.67 & 0.7368 & 28.7223 & 5470.21 & 0.1535 & 20.66 & 0.1842 \\
\hline 41.0552 & 6448.09 & 1.2280 & 20.99 & 1.4736 & 29.4914 & 9333.99 & 0.1279 & 35.25 & 0.1535 \\
\hline 43.1614 & 5322.05 & 1.2280 & 17.32 & 1.4736 & 36.1282 & 6006.31 & 0.3070 & 22.68 & 0.3684 \\
\hline & & & & & 39.1432 & 6627.46 & 6.1402 & 25.03 & 7.3682 \\
\hline & & & & & 45.8451 & 3769.70 & 0.3070 & 14.23 & 0.3684 \\
\hline
\end{tabular}


In Figure 5, for FE-72T, similar peaks as that of FE72 appeared. However, the peak at $29.4^{\circ}$ has higher intensity, and become sharper. Other peaks increased slightly. Table 2 also shows the peak list for FE-72T. Again, these results show that FE-72T is also partially crystalline and the crystallinity is in $\gamma$-phase form. The increase of relative intensity of the above mentioned common peaks and specifically the increase in the peak at $29.4^{\circ}$ show that the crystallinity of FE-72T is slightly more than that of FE-72. Having new peaks with very low FWHM and tip width and considerable intensity also shows more crystallinity in FE-72T. Again the above results show that after tensile the crystallinity increases due to SIC. Once more, these results also confirm the tensile results that showed SIC during tensile test for FE.

Again, the amorphous hollows of FE-72T at $6.69^{\circ}$ and $16.69^{\circ}$ decreased compared to that of FE-72. It is due to increase in crystallinity due to SIC in FE-72T and decreasing amorphous part of FE. In Figure 5, comparison between FE-T and FE-72T show that the intensity of peaks at $28^{\circ}, 64^{\circ}, 29.42^{\circ}, 39.22^{\circ}$ and $47.08^{\circ}$ increased. Relative intensity of common peaks in them also shows slightly more crystallinity in FE-72T. Once again these results show that due to aging at high temperature, $\gamma$-phase crystallinity increased. However, the peaks at $9.51^{\circ}$ and $14.46^{\circ}$ increased slightly in FE-T compared to FE-72T. Comparing the intensity of amorphous hollows of all four samples in Figure 5, it shows that the crystallinity intensity is in the order of FE-72T $>$ FE-T $>$ FE $>$ FE-72. Therefore, SIC in tensile test samples increased the crystallinity compared to non-tensile test samples.

XRD of CB/FE Figure 6 shows XRD spectra of CB/ $\mathrm{FE}$ and $\mathrm{CB} / \mathrm{FE}-72$ before and after tensile test. The figure shows a considerable peak for $\mathrm{CB} / \mathrm{FE}$ at $29.45^{\circ}$, a peak at $39.31^{\circ}$ and a few small peaks which are $\gamma$-phase crystallinity peaks. Table 3 shows the peak list for $\mathrm{CB} /$ FE. These peaks show that $\mathrm{CB} / \mathrm{FE}$ is slightly crystalline and in $\gamma$-phase form.

An XRD spectra of CB/FE-T in the same figure shows many sharp and intense peaks. Table 3 also shows peak list of them. The high intensity and very sharp peaks show very high degree of crystallinity compared to that of $\mathrm{CB} / \mathrm{FE}$. A very low FWHM and tip width with high peaks indicate that the structure have very large crystals and is highly ordered. All of these peaks belonged to $\gamma$-phase ${ }^{19-23}$ of VDF segments and TFE segments. Some peaks of VDF monomer are overlapped with peaks of TFE segments. The spectra of the TFE peaks were reported by Tieyuan et al. ${ }^{25}$ Therefore, in CB/FE-T, $\gamma$-phase and TFE crystallinity segments increased considerably compared to $\mathrm{CB} / \mathrm{FE}$. In $\mathrm{CB} / \mathrm{FE}-\mathrm{T}$, the amorphous hol-

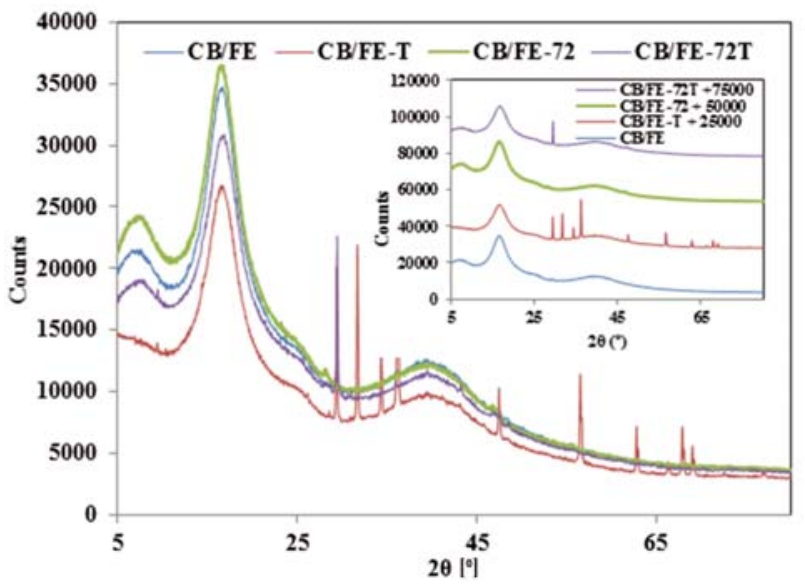

Figure 6. An XRD spectra of $\mathrm{CB} / \mathrm{FE}$ and $\mathrm{CB} / \mathrm{FE}-72$ before and after tensile test (overlaid and separated)

lows at $16.64^{\circ}$ decreased and the one at $6.88^{\circ}$ almost disappeared compared to $\mathrm{CB} / \mathrm{FE}$. This again shows the increase in crystallinity and decrease in amorphous portion. Once more, these results show that after tensile test, the crystallinity and crystal size increased to a great extent due to SIC.

Comparing CB/FE-T of Figure 6 and FE-T of Figure 5 shows that the SIC in the presence of $\mathrm{CB}$ is much more compared to unfilled FE. Figure 6 also shows that for $\mathrm{CB} / \mathrm{FE}-72$, there are some main peaks. The peak list for this figure is tabulated in Table 4. Similar to FE-72, all of these peaks show $\gamma$-phase crystallinity of VDF segments in FE, especially peaks at $28.13^{\circ}$ and $46.76^{\circ}$ are characteristic of $\gamma$-phase. Like FE-72, CB/FE-72 is partially crystalline. $\gamma$-phase crystallinity increased in $\mathrm{CB} /$ FE-72 in comparison to $\mathrm{CB} / \mathrm{FE}$. These results are the same as that of FE and FE-72. The peak at around $29.3^{\circ}$ decreased in $\mathrm{CB} / \mathrm{FE}-72$ is probably due to aging at high temperature in the presence of $\mathrm{CB}$ compared to $\mathrm{CB} / \mathrm{FE}$.

In Figure 6, for $\mathrm{CB} / \mathrm{FE}-72 \mathrm{~T}$, some of the peaks appeared are the same as that of $\mathrm{CB} / \mathrm{FE}-\mathrm{T}$ peaks. However, the smaller peaks of $\mathrm{CB} / \mathrm{FE}-\mathrm{T}$ did not appear in $\mathrm{CB} /$ FE-72T. The peak at $29.46^{\circ}$ is sharp and intense. Table 4 also shows the peak list of $\mathrm{CB} / \mathrm{FE}-72 \mathrm{~T}$. The above results show that $\mathrm{CB} / \mathrm{FE}-72 \mathrm{~T}$ is also partially crystalline and the crystallinity is in $\gamma$-phase form. The peaks especially at $28.25^{\circ}$ and $47.54^{\circ}$ are due to $\gamma$-phase. Similar to FE-72 and FE-72T, the crystallinity of CB/FE-72T is more than that of $\mathrm{CB} / \mathrm{FE}-72$. The new peaks in $\mathrm{CB} /$ FE-72T compared to $\mathrm{CB} / \mathrm{FE}-72$ has very low FWHM and tip width. The amorphous hollow appeared at $7.57^{\circ}$ and $16.73^{\circ}$ decreased in $\mathrm{CB} / \mathrm{FE}-72 \mathrm{~T}$ compared to $\mathrm{CB} /$ FE-72 indicates increase in crystallinity and decrease in amorphous portion.

Table 2. XRD peak list of FE-72 and FE-72T

\begin{tabular}{|c|c|c|c|c|c|c|c|c|c|}
\hline \multicolumn{5}{|c|}{ FE-72 } & \multicolumn{5}{|c|}{ FE-72T } \\
\hline Pos. $\left[{ }^{\circ} 2 \theta\right]$ & Height [cts] & $\begin{array}{c}\text { FWHM } \\
\left.\text { Left [ }{ }^{\circ} 2 \theta\right]\end{array}$ & $\begin{array}{c}\text { Rel. Int. } \\
{[\%]}\end{array}$ & Tip Width & $\begin{array}{l}\text { Pos. } \\
{\left[{ }^{\circ} 2 \theta\right]}\end{array}$ & Height [cts] & $\begin{array}{c}\text { FWHM } \\
\left.\text { Left [ }{ }^{\circ} 2 \theta\right]\end{array}$ & $\begin{array}{c}\text { Rel. Int. } \\
{[\%]}\end{array}$ & Tip Width \\
\hline 5.9319 & 20509.41 & 0.8187 & 59.57 & 0.9824 & 6.6919 & 15257.79 & 1.8420 & 55.42 & 2.2105 \\
\hline 7.1630 & 21458.28 & 2.0467 & 62.33 & 2.4561 & 14.4006 & 18200.94 & 0.1535 & 66.12 & 0.1842 \\
\hline 16.5411 & 34428.24 & 2.0467 & 100.00 & 2.4561 & 16.6918 & 27528.97 & 1.1257 & 100.00 & 1.3508 \\
\hline 28.1703 & 7472.34 & 0.5117 & 21.70 & 0.6140 & 29.0018 & 5754.45 & 0.1535 & 20.90 & 0.1842 \\
\hline 39.2622 & 8527.58 & 2.2514 & 24.77 & 2.7017 & 29.4286 & 13166.24 & 0.1279 & 47.83 & 0.1535 \\
\hline 42.1214 & 7454.00 & 2.0467 & 21.65 & 2.4561 & 39.3155 & 7237.23 & 1.6374 & 26.29 & 1.9649 \\
\hline 46.7860 & 4879.88 & 0.5117 & 14.17 & 0.6140 & 42.2253 & 6078.87 & 2.0467 & 22.08 & 2.4561 \\
\hline 55.5212 & 1665.44 & 1.2280 & 4.84 & 1.4736 & 47.0789 & 4009.30 & 0.2047 & 14.56 & 0.2456 \\
\hline
\end{tabular}


Table 3. XRD peak list of $\mathrm{CB} / \mathrm{FE}$ and $\mathrm{CB} / \mathrm{FE}-\mathrm{T}$

\begin{tabular}{|c|c|c|c|c|c|c|c|c|c|}
\hline \multicolumn{5}{|c|}{ CB/FE } & \multicolumn{5}{|c|}{ CB/FE-T } \\
\hline Pos. $\left[{ }^{\circ} 2 \theta\right]$ & Height [cts] & $\begin{array}{l}\text { FWHM } \\
\left.\text { Left [ }{ }^{\circ} 2 \theta\right]\end{array}$ & $\begin{array}{c}\text { Rel. Int. } \\
{[\%]}\end{array}$ & Tip Width & $\begin{array}{l}\text { Pos. } \\
{\left[{ }^{\circ} 2 \theta\right]}\end{array}$ & Height [cts] & $\begin{array}{c}\text { FWHM } \\
\left.\text { Left [ }{ }^{\circ} 2 \theta\right]\end{array}$ & $\begin{array}{c}\text { Rel. Int. } \\
{[\%]}\end{array}$ & Tip Width \\
\hline 6.6402 & 15892.81 & 1.6374 & 60.01 & 1.9649 & 6.1345 & 11347.34 & 2.4561 & 42.51 & 2.9473 \\
\hline 7.6846 & 15679.07 & 0.8187 & 59.21 & 0.9824 & 9.3912 & 10793.49 & 0.1535 & 40.44 & 0.1842 \\
\hline 9.5119 & 14460.41 & 0.0768 & 54.60 & 0.0921 & 16.6367 & 23584.99 & 1.2280 & 88.36 & 1.4736 \\
\hline 14.4596 & 19491.94 & 0.0768 & 73.60 & 0.0921 & 17.4084 & 21517.67 & 0.5117 & 80.62 & 0.6140 \\
\hline 16.7321 & 26482.39 & 1.8420 & 100.00 & 2.2105 & 24.9809 & 7239.29 & 1.6374 & 27.12 & 1.9649 \\
\hline 28.7223 & 5470.21 & 0.1535 & 20.66 & 0.1842 & 26.1235 & 6812.90 & 0.1535 & 25.53 & 0.1842 \\
\hline 29.4914 & 9333.99 & 0.1279 & 35.25 & 0.1535 & 29.3956 & 17221.39 & 0.1023 & 64.52 & 0.1228 \\
\hline 36.1282 & 6006.31 & 0.3070 & 22.68 & 0.3684 & 31.7095 & 18995.92 & 0.1279 & 71.17 & 0.1535 \\
\hline 39.1432 & 6627.46 & 6.1402 & 25.03 & 7.3682 & 34.3642 & 11201.93 & 0.1023 & 41.97 & 0.1228 \\
\hline 45.8451 & 3769.70 & 0.3070 & 14.23 & 0.3684 & 36.1950 & 26690.92 & 0.1535 & 100.00 & 0.1842 \\
\hline & & & & & 39.3631 & 6730.78 & 3.2748 & 25.22 & 3.9297 \\
\hline & & & & & 43.1504 & 5796.95 & 0.6140 & 21.72 & 0.7368 \\
\hline & & & & & 47.4793 & 7327.55 & 0.1023 & 27.45 & 0.1228 \\
\hline & & & & & 56.5266 & 8526.38 & 0.1248 & 31.94 & 0.1498 \\
\hline & & & & & 56.7009 & 4649.37 & 0.0624 & 17.42 & 0.0749 \\
\hline & & & & & 62.7965 & 4154.54 & 0.0936 & 15.57 & 0.1123 \\
\hline & & & & & 62.9637 & 2372.57 & 0.0936 & 8.89 & 0.1123 \\
\hline & & & & & 66.3063 & 1283.19 & 0.1248 & 4.81 & 0.1498 \\
\hline & & & & & 67.8837 & 4153.92 & 0.1248 & 15.56 & 0.1498 \\
\hline & & & & & 68.0889 & 2305.54 & 0.0624 & 8.64 & 0.0749 \\
\hline & & & & & 69.0186 & 2579.34 & 0.0936 & 9.66 & 0.1123 \\
\hline & & & & & 69.2086 & 1468.91 & 0.0936 & 5.50 & 0.1123 \\
\hline & & & & & 72.5615 & 284.64 & 0.3744 & 1.07 & 0.4493 \\
\hline & & & & & 76.8946 & 619.94 & 0.0936 & 2.32 & 0.1123 \\
\hline
\end{tabular}

Table 4. XRD peak list of CB/FE-72 and CB/FE-72T

\begin{tabular}{|c|c|c|c|c|c|c|c|c|c|}
\hline \multicolumn{9}{|c}{ CB/FE-72 } & \multicolumn{4}{c|}{ CB/FE-72T } \\
\hline Pos. $\left[^{\circ} 2 \theta\right]$ & Height [cts] & $\begin{array}{c}\text { FWHM } \\
\left.\text { Left [ }{ }^{\circ} 2 \theta\right]\end{array}$ & $\begin{array}{c}\text { Rel. Int. } \\
{[\%]}\end{array}$ & Tip Width & $\begin{array}{c}\text { Pos. } \\
{\left[{ }^{\circ} 2 \theta\right]}\end{array}$ & Height [cts] & $\begin{array}{c}\text { FWHM } \\
\left.\text { Left [ }{ }^{\circ} 2 \theta\right]\end{array}$ & $\begin{array}{c}\text { Rel. Int. } \\
{[\%]}\end{array}$ & $\begin{array}{c}\text { Tip Width } \\
{[\%}\end{array}$ \\
\hline 6.1259 & 19496.08 & 1.0234 & 60.13 & 1.2280 & 7.5715 & 14999.44 & 1.6374 & 56.03 & 1.9649 \\
\hline 7.3389 & 20237.82 & 0.7164 & 62.42 & 0.8596 & 9.4618 & 14380.04 & 0.0768 & 53.71 & 0.0921 \\
\hline 15.6729 & 29441.39 & 0.7164 & 90.81 & 0.8596 & 16.7273 & 26772.52 & 1.4327 & 100.00 & 1.7192 \\
\hline 16.5432 & 32420.79 & 0.9210 & 100.00 & 1.1052 & 25.5737 & 8498.00 & 0.9210 & 31.74 & 1.1052 \\
\hline 25.2695 & 9809.72 & 2.0467 & 30.26 & 2.4561 & 28.2500 & 6731.50 & 0.4093 & 25.14 & 0.4912 \\
\hline 28.1276 & 7816.60 & 0.3070 & 24.11 & 0.3684 & 29.4621 & 18641.46 & 0.1279 & 69.63 & 0.1535 \\
\hline 39.5827 & 8214.34 & 1.2280 & 25.34 & 1.4736 & 30.9926 & 6011.51 & 0.1535 & 22.45 & 0.1842 \\
\hline 42.8146 & 6987.13 & 2.4561 & 21.55 & 2.9473 & 39.4943 & 7680.51 & 0.3070 & 28.69 & 0.3684 \\
\hline 46.7646 & 4819.12 & 0.5117 & 14.86 & 0.6140 & 43.2248 & 6502.88 & 0.2047 & 24.29 & 0.2456 \\
\hline 55.6646 & 1685.61 & 0.6140 & 5.20 & 0.7368 & 47.5493 & 4268.30 & 0.1535 & 15.94 & 0.1842 \\
\hline & & & & & 48.5309 & 3541.39 & 0.2047 & 13.23 & 0.2456 \\
\hline
\end{tabular}

In Figure 6, comparing $\mathrm{CB} / \mathrm{FE}-\mathrm{T}$ and $\mathrm{CB} / \mathrm{FE}-72 \mathrm{~T}$ shows that the intensive and sharp peaks of $\mathrm{CB} / \mathrm{FE}-\mathrm{T}$ changed to small peaks for CB/FE-72T, except the peak at $29.46^{\circ}$. These results indicate that due to aging at high temperature in the presence of $\mathrm{CB}$, the crystallinity of tensile tested elastomer is reduced sensibly. Once again, comparing the intensity of the amorphous hollows of all four samples in Figure 6 indicates that the crystalline intensity is as follows: $\mathrm{CB} / \mathrm{FE}-\mathrm{T}>\mathrm{CB} / \mathrm{FE}-72 \mathrm{~T}>\mathrm{CB} /$ $\mathrm{FE}>\mathrm{CB} / \mathrm{FE}-72$. Therefore, $\mathrm{SIC}$ in tensile test samples increased the crystallinity compared to non-tensile test samples.

XRD of CNT/FE Figure 7 shows XRD spectra of CNT/ FE and CNT/FE-72 before and after tensile test. Table 5 shows the peak list for CNT/FE. These results show that $\mathrm{CNT} / \mathrm{FE}$ is slightly crystalline and the crystallinity is in $\gamma$-phase form, the reasons are the same as those mentioned for $\mathrm{CB} / \mathrm{FE}$. The peaks at $26.02^{\circ}$ and $26.28^{\circ}$ are the overlapped peaks of $\mathrm{CNT}^{16}$ and $\gamma$-phase peak ${ }^{19}$.

CNT/FE-T XRD spectra presented in the same figure and Table 5 shows the peak list of it. Again, based on these results, CNT/FE-T and CNT/FE shows the same properties that $\mathrm{CB} / \mathrm{FE}-\mathrm{T}$ and $\mathrm{CB} / \mathrm{FE}$ do. CNT/FE-T shows very high degree of crystallinity and highly ordered large crystals. These results show that the degree of

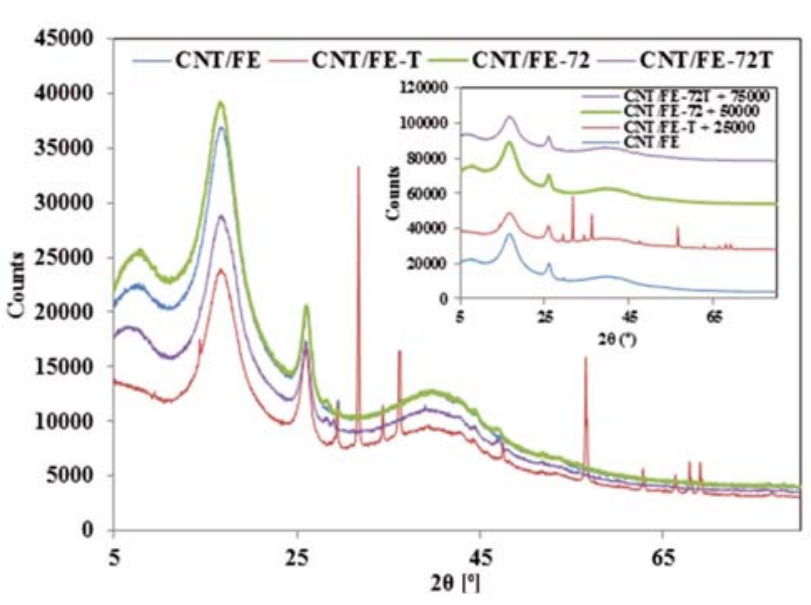

Figure 7. An XRD spectra of CNT/FE and CNT/FE-72 before and after tensile test (overlaid and separated)

crystallinity increases with SIC in the presence of CNT. Comparing CNT/FE-T and CNT/FE of Figure 7 indicates that the SIC in CNT/FE-T is considerably higher. Figure 7 also shows that for CNT/FE-72, there are new peaks at $28.18^{\circ}, 46.88^{\circ}$ and $53.60^{\circ}$. The peak list is presented in Table 6. All of these peaks show $\gamma$-phase crystallinity with considerable intensity which indicates partial 
Table 5. XRD peak list of CNT/FE and CNT/FE-T

\begin{tabular}{|c|c|c|c|c|c|c|c|c|c|}
\hline \multicolumn{5}{|c|}{ CNT/FE } & \multicolumn{5}{|c|}{ CNT/FE-T } \\
\hline Pos. [ $\left.{ }^{\circ} 2 \theta\right]$ & Height [cts] & $\begin{array}{c}\text { FWHM } \\
\left.\text { Left [ }{ }^{\circ} 2 \theta\right]\end{array}$ & $\begin{array}{c}\text { Rel. Int. } \\
{[\%]}\end{array}$ & Tip Width & $\begin{array}{l}\text { Pos. } \\
{\left[{ }^{\circ} 2 \theta\right]}\end{array}$ & Height [cts] & $\begin{array}{c}\text { FWHM } \\
\left.\text { Left [ }{ }^{\circ} 2 \theta\right]\end{array}$ & $\begin{array}{c}\text { Rel. Int. } \\
{[\%]}\end{array}$ & Tip Width \\
\hline 7.5435 & 18117.89 & 1.8420 & 55.46 & 2.2105 & 14.3605 & 14335.27 & 0.0768 & 47.17 & 0.0921 \\
\hline 16.7333 & 32667.22 & 2.0467 & 100.00 & 2.4561 & 16.6636 & 20709.47 & 1.9444 & 68.15 & 2.3333 \\
\hline 26.0174 & 16115.57 & 0.3070 & 49.33 & 0.3684 & 25.9181 & 13320.50 & 0.7675 & 43.83 & 0.9210 \\
\hline 26.2798 & 15321.18 & 0.2047 & 46.90 & 0.2456 & 29.3762 & 8631.16 & 0.1279 & 28.40 & 0.1535 \\
\hline 29.4754 & 7762.76 & 0.1279 & 23.76 & 0.1535 & 31.6985 & 30389.63 & 0.1279 & 100.00 & 0.1535 \\
\hline 39.6843 & 8512.91 & 0.6140 & 26.06 & 0.7368 & 34.3474 & 8279.77 & 0.1279 & 27.25 & 0.1535 \\
\hline 42.9767 & 7575.57 & 0.6140 & 23.19 & 0.7368 & 36.1779 & 20132.82 & 0.1535 & 66.25 & 0.1842 \\
\hline 44.6300 & 6495.15 & 0.4093 & 19.88 & 0.4912 & 39.2850 & 6397.88 & 0.8187 & 21.05 & 0.9824 \\
\hline 45.9473 & 5221.49 & 0.3070 & 15.98 & 0.3684 & 42.7305 & 5848.60 & 0.8187 & 19.25 & 0.9824 \\
\hline 53.6761 & 2409.06 & 0.8187 & 7.37 & 0.9824 & 44.2676 & 5169.91 & 0.4093 & 17.01 & 0.4912 \\
\hline & & & & & 47.4648 & 5015.24 & 0.1279 & 16.50 & 0.1535 \\
\hline & & & & & 53.2158 & 2115.18 & 0.6140 & 6.96 & 0.7368 \\
\hline & & & & & 56.5192 & 12759.13 & 0.1248 & 41.99 & 0.1498 \\
\hline & & & & & 56.6863 & 6875.02 & 0.0936 & 22.62 & 0.1123 \\
\hline & & & & & 62.7775 & 2495.84 & 0.0936 & 8.21 & 0.1123 \\
\hline & & & & & 66.3065 & 2009.33 & 0.0936 & 6.61 & 0.1123 \\
\hline & & & & & 67.8663 & 3153.49 & 0.1248 & 10.38 & 0.1498 \\
\hline & & & & & 68.0552 & 1620.74 & 0.0936 & 5.33 & 0.1123 \\
\hline & & & & & 69.0089 & 3140.91 & 0.1248 & 10.34 & 0.1498 \\
\hline & & & & & 69.1981 & 1650.45 & 0.0936 & 5.43 & 0.1123 \\
\hline & & & & & 76.8753 & 590.10 & 0.0936 & 1.94 & 0.1123 \\
\hline
\end{tabular}

crystallinity. The peak at $53.60^{\circ}$ is also probably due to $\gamma$-phase crystallinity. Due to high temperature, $\gamma$-phase crystallinity increased in CNT/FE-72 compared to CNT/ $\mathrm{FE}$. The results are the same as that of $\mathrm{FE}$ and $\mathrm{CB} / \mathrm{FE}$.

Figure 7 show XRD spectra of CNT/FE-72T too. Table 6 also shows the peak list for $\mathrm{CNT} / \mathrm{FE}-72 \mathrm{~T}$. Based on these results and similar to $\mathrm{CB} / \mathrm{FE}-72$ and $\mathrm{CB} / \mathrm{FE}-72 \mathrm{~T}$, the following conclusios can be made: $\mathrm{CNT} / \mathrm{FE}-72 \mathrm{~T}$ is slightly crystalline in the form of $\gamma$-phase, especially the peaks at $28.18^{\circ}, 28.98^{\circ}, 46.96^{\circ}$ and $53.89^{\circ}$ are indicative of $\gamma$-phase. The crystallinity degree in CNT/FE-72T slightly increased and amorphous parts decreased compared to $\mathrm{CNT} / \mathrm{FE}-72$. CNT/FE-72T has crystals with less size compared to CNT/FE-T. Comparison of CNT/ FE-T and CNT/FE-72T again shows that due to aging at high temperature in the presence of CNT too, the crystallinity of stretched elastomer reduced significantly.

The comparison of amorphous hollows of all samples shows that the degree of crystallinity has the following order among the samples: CNT/FE-T > CNT/FE-72T > $\mathrm{CNT} / \mathrm{FE}>\mathrm{CNT} / \mathrm{FE}-72$ which is the same trend as $\mathrm{CB} /$ FE. This order shows that SIC increased the crystallinity for CNT/FE. Shear field (high shear mixing during compounding and molding) promotes the formation of polar $\gamma$-crystalline phase.

Figure 8 shows the FESEM images of CNT/FE (the razor cut cross section surface) and $\mathrm{CB} / \mathrm{FE}-48$. The very good distribution and dispersion of $\mathrm{CNT}$ and $\mathrm{CB}$ in $\mathrm{FE}$ can be seen in this figure.

Verifying crystalinity and studying chemical degradation In our before study ${ }^{26}$, we verified the crystalinity of some of the above mentioned FE and fillers/FE, by Dynamic Mechanical Analysis (DMA), Differential Scanning Calorimetry (DSC) and X-ray diffraction (XRD). In addition in another study ${ }^{27}$, for the before mentioned FE and fillers/FE, we revealed the effect of heat aging on chemical degradation by Energy Dispersive X-Ray (EDX). Verifying thermal properties of fluoroelastomer using carbon nanotubes in presence of air and under nitrogen flow is the other study ${ }^{\mathbf{2 8}}$.

Table 6. XRD peak list of CNT/FE-72 and CNT/FE-72T

\begin{tabular}{|c|c|c|c|c|c|c|c|c|c|}
\hline \multicolumn{5}{|c|}{ CNT/FE-72 } & \multicolumn{5}{|c|}{ CNT/FE-72T } \\
\hline Pos. $\left[{ }^{\circ} 2 \theta\right]$ & Height [cts] & $\begin{array}{c}\text { FWHM } \\
\left.\text { Left [ }{ }^{\circ} 2 \theta\right]\end{array}$ & $\begin{array}{c}\text { Rel. Int. } \\
{[\%]}\end{array}$ & $\begin{array}{c}\text { Tip } \\
\text { Width }\end{array}$ & $\begin{array}{l}\text { Pos. } \\
{\left[{ }^{\circ} 2 \theta\right]}\end{array}$ & Height [cts] & $\begin{array}{c}\text { FWHM } \\
\text { Left }\left[{ }^{\circ} 2 \theta\right]\end{array}$ & $\begin{array}{c}\text { Rel. Int. } \\
{[\%]}\end{array}$ & $\begin{array}{c}\text { Tip } \\
\text { Width }\end{array}$ \\
\hline 6.1684 & 20004.89 & 1.2280 & 57.47 & 1.4736 & 6.5253 & 14828.97 & 1.4327 & 59.39 & 1.7192 \\
\hline 7.6807 & 21123.57 & 1.4327 & 60.69 & 1.7192 & 7.7059 & 14579.13 & 0.8187 & 58.39 & 0.9824 \\
\hline 16.6414 & 34806.38 & 1.8420 & 100.00 & 2.2105 & 16.6800 & 24969.72 & 1.1257 & 100.00 & 1.3508 \\
\hline 26.0048 & 16299.59 & 0.7164 & 46.83 & 0.8596 & 17.9897 & 21180.32 & 0.6140 & 84.82 & 0.7368 \\
\hline 26.6576 & 11860.57 & 0.0768 & 34.08 & 0.0921 & 25.9566 & 13298.05 & 0.5117 & 53.26 & 0.6140 \\
\hline 28.1823 & 7608.46 & 0.4093 & 21.86 & 0.4912 & 28.1842 & 6444.93 & 0.3070 & 25.81 & 0.3684 \\
\hline 39.7215 & 8419.32 & 4.9121 & 24.19 & 5.8946 & 28.9777 & 6414.38 & 0.2047 & 25.69 & 0.2456 \\
\hline 42.9086 & 7558.15 & 0.8187 & 21.71 & 0.9824 & 39.1045 & 7350.81 & 0.6140 & 29.44 & 0.7368 \\
\hline 44.5437 & 6628.75 & 0.4093 & 19.04 & 0.4912 & 42.7602 & 6626.04 & 0.6140 & 26.54 & 0.7368 \\
\hline 46.8803 & 5003.85 & 0.6140 & 14.38 & 0.7368 & 44.3330 & 5666.57 & 0.5117 & 22.69 & 0.6140 \\
\hline 51.9204 & 2740.42 & 0.6140 & 7.87 & 0.7368 & 46.9559 & 4472.47 & 0.5117 & 17.91 & 0.6140 \\
\hline 53.5991 & 2396.27 & 0.6140 & 6.88 & 0.7368 & 53.8893 & 2042.53 & 1.2280 & 8.18 & 1.4736 \\
\hline
\end{tabular}


(a)

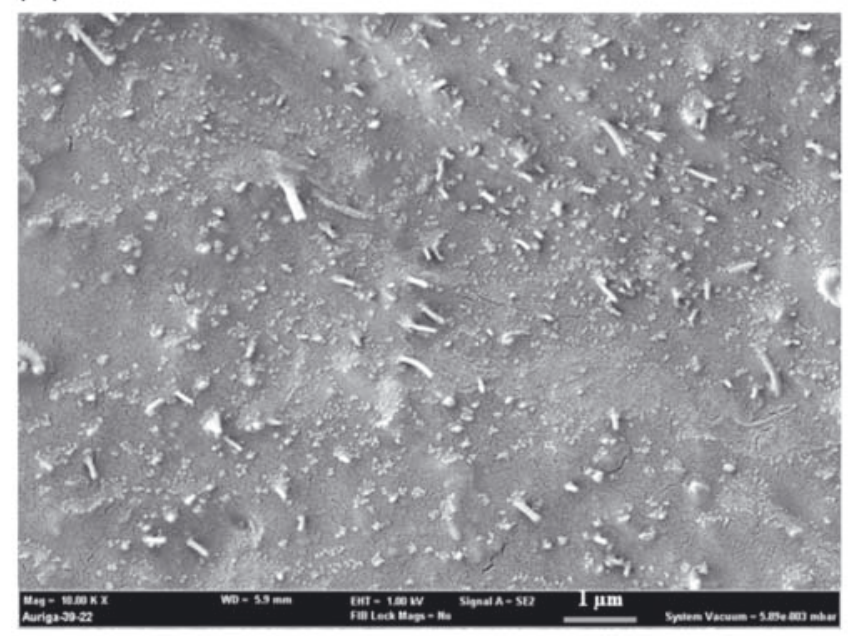

(b)

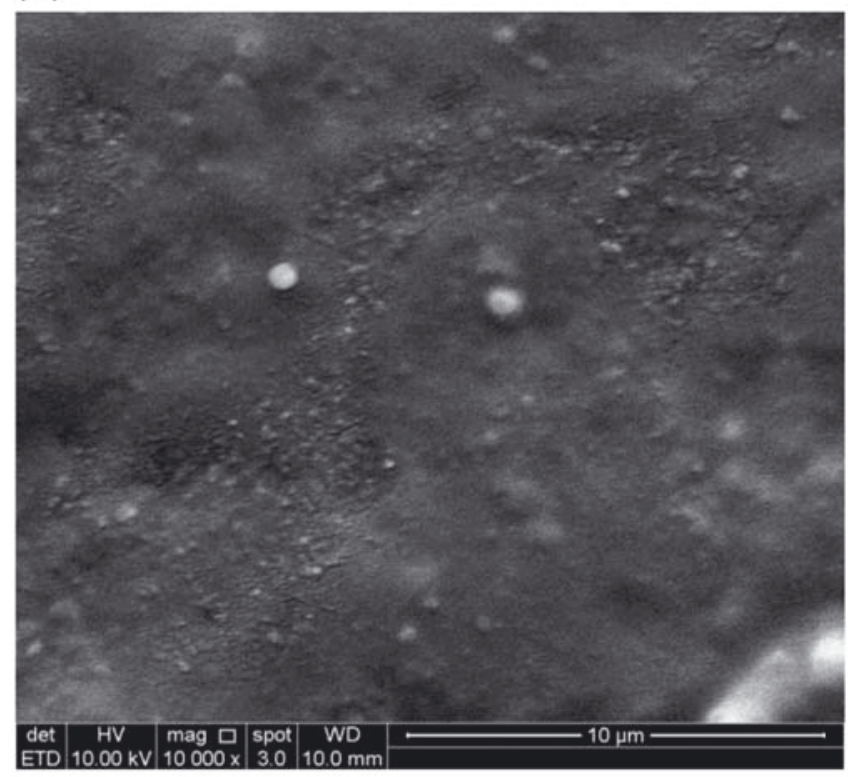

Figure 8. FESEM images of (a) CNT/FE (the razor cut cross section surface) and (b) CB/FE-48

\section{CONCLUSIONS}

Comparing tensile properties of unaged and heat air aged $\mathrm{FE}, \mathrm{CB} / \mathrm{FE}$ and $\mathrm{CNT} / \mathrm{FE}$ show that $\mathrm{CNT}$ improved tensile properties of FE before and after aging. The increase in NM and TM at fixed strain for aged and un-aged $\mathrm{FE}$ composites are in the order of $\mathrm{CNT} / \mathrm{FE}>$ $\mathrm{CB} / \mathrm{FE}>\mathrm{FE}$. TS has the order of $\mathrm{CNT} / \mathrm{FE}>\mathrm{CB} / \mathrm{FE}$ $>\mathrm{FE}$, while $\mathrm{EB}$ has the reverse order: $\mathrm{FE}>\mathrm{CB} / \mathrm{FE}$ $>\mathrm{CNT} / \mathrm{FE}$. All samples show SIC in the stress-strain curves; in $\mathrm{FE}, \mathrm{CB} / \mathrm{FE}$ and $\mathrm{CNT} / \mathrm{FE}$ the strain started at $200 \%, 100 \%$ and $25 \%$ respectively. XRD results indicate that $\mathrm{FE}, \mathrm{CB} / \mathrm{FE}$ and $\mathrm{CNT} / \mathrm{FE}$ are in $\gamma$-phase form before and after aging (original compound). Un-aged specimens that undergo tensile testing displayed this characteristic as well before and after the test. The tensile tested, aged specimens were also in $\gamma$-phase form. However, the degree of crystallinity is dependent on the conditions. TFE crystalline peaks were also observed. Non-aging or aging alone causes slight crystallinity with low crystal size. Tensile test alone increases the degree of crystallinity and crystal size considerably in non-aged
CB/FE, CNT/FE and FE samples. Tensile test also proves that aged samples have less degree of crystallinity after testing compared to non-aged samples. XRD results confirm tensile results which shows SIC after tensile test.

\section{ACKNOWLEDGEMENTS}

We thank the University of Malaya as the work reported in this paper was funded under the grant numbers FRGS (FP021-2013A) and BKP (BK005-2014).

\section{LITERATURE CITED}

1. Endo, M., Noguchi, T., Ito, M., Takeuchi, K., Hayashi, T., Kim, Y.A., Wanibuchi, T., Jinnai, H., Terrones, M. \& Dresselhaus, M.S. (2008). Extreme-performance rubber nanocomposites for probing and excavating deep oil resources using multi-walled carbon nanotubes. Adv. Func. Mat. 18, 3403-3409. DOI: $10.1002 /$ adfm.200801136.

2. Noguchi, T., Ueki, H., Inukai, S., Iinou, S. \& Ito, M. (2011). U.S Patent No. 2011/0160375. Washington, D.C.: U.S. Patent and Trademark Office.

3. Ito, M., Noguchi, T., Ueki, H., Takeuchi, K. \& Endo, M. (2011). Carbon nanotube enables quantum leap in oil recovery. Mater. Res. Bull. 46, 1480-1484. DOI: 10.1016/j. materresbull.2011.04.028.

4. Faulkner, W.R., Mumby, K.J., Fischer, A., Jozokos, T. \& Zhou, S. (2009). Multiwall carbon nanotube reinforcement of HNBR and FKM. Proc. of the Fall 176th Technical meeting of the rubber division, Pittsburgh, PA, USA, 13-15 Oct.

5. Wang, Y., Liu, L., Luo, Y. \& Jia, D. (2009). Aging behavior and thermal degradation of fluoroelastomer reactive blends with poly-phenol hydroxy EPDM. Polym. Degrad. Stab. 94, 443-449. DOI: 10.1016/j.polymdegradstab.2008.11.007.

6. Smith, G., Park, D., Titchener, K., Davies, R. \& West, R. (1995). Surface studies of oil-seal degradation. Appl. Surf. Sci. 90, 357-371. DOI: 10.1016/0169-4332(95)00165-4.

7. Mago, G., Fisher, F.T. \& Kalyon, D.M. (2009). Deformation-induced crystallization and associated morphology development of carbon nanotube-PVDF nanocomposites. J. Nanosci. Nanotechnol. 9, 3330-3340. DOI: http://dx.doi. org/10.1166/jnn.2009.VC08

8. Huang, S., Yee, W.A., Tjiu, W.C., Liu, Y., Kotaki, M., Boey, Y.C.F., Ma, J., Liu, T. \& Lu, X. (2008). Electrospinning of polyvinylidene difluoride with carbon nanotubes: synergistic effects of extensional force and interfacial interaction on crystalline structures. Langmuir 24, 13621-13626. DOI: 10.1021/ la8024183.

9. Maiti, M. \& Bhowmick, A.K. (2007). Dynamic viscoelastic properties of fluoroelastomer/clay nanocomposites. Polym. Eng. Sci. 47, 1777-1787. DOI: 10.1002/pen.20877.

10. Chae, D.W. \& Hong, S.M. (2011). Rheology, crystallization behavior under shear, and resultant morphology of PVDF/ multiwalled carbon nanotube composites. Macromol. Res. 19, 326-331. DOI: 10.1007/s13233-011-0403-1.

11. Yang, J., Wang, J., Zhang, Q., Chen, F., Deng, H., Wang, K. \& Fu, Q. (2011). Cooperative effect of shear and nanoclay on the formation of polar phase in poly (vinylidene fluoride) and the resultant properties. Polymer 52, 4970-4978. DOI: 10.1016/j.polymer.2011.08.051.

12. Buckley, J., Cebe, P., Cherdack, D., Crawford, J., Ince, B.S., Jenkins, M., Pan, J., Reveley, M., Washington, N. \& Wolchover, N. (2006). Nanocomposites of poly(vinylidene fluoride) with organically modified silicate. Polymer 47, 2411-2422. DOI: http://dx.doi.org/10.1016/j.polymer.2006.02.012

13. Andrew, J.S. \& Clarke, D.R. (2008). Effect of electrospinning on the ferroelectric phase content of polyvinylidene difluoride fibers. Langmuir 24, 670-672. DOI: 10.1021/la7035407. 
14. Huang, F., Wei, Q., Wang, J., Cai, Y. \& Huang, Y. (2008). Effect of temperature on structure, morphology and crystallinity of PVDF nanofibers via electrospinning. e-Polym 8, 1758. DOI: 10.1515/epoly.2008.8.1.1758.

15. Yee, W.A., Nguyen, A.C., Lee, P.S., Kotaki, M., Liu, Y., Tan, B.T., Mhaisalkar, S. \& Lu, X. (2008). Stress-induced structural changes in electrospun polyvinylidene difluoride nanofibers collected using a modified rotating disk. Polymer 49, 4196-4203. DOI: http://dx.doi.org/10.1016/j.polymer.2008.07.032

16. Pham, T.T., Sridhar, V. \& Kim, J.K. (2009). Fluoroelastomer-MWNT nanocomposites-1: Dispersion, morphology, physico-mechanical, and thermal properties. Polym. Compos. 30, 121-130. DOI: 10.1002/pc.20521.

17. Shanmugharaj, A., Bae, J., Lee, K.Y., Noh, W.H., Lee, S.H. \& Ryu, S.H. (2007). Physical and chemical characteristics of multiwalled carbon nanotubes functionalized with aminosilane and its influence on the properties of natural rubber composites. Compos. Sci. Technol. 67, 1813-1822. DOI: 10.1016/j.compscitech.2006.10.021.

18. Freimuth, H., Sinn, C. \& Dettenamaier, M. (1996). Structure and deformation behaviour of a vinylidene fluoride-tetrafluoroethylene- hexafluoropropylene terpolymer. Polymer 37, 831-836. DOI: http://dx.doi.org/10.1016/0032-3861(96)87261-2

19. Satapathy, S., Pawar, S., Gupta, P. \& Varma, K. (2011). Effect of annealing on the phase transition in poly (vinylidene fluoride) films prepared using polar solvent. Bull. Mater. Sci. 34, 727-733. DOI: http://dx.doi.org/10.1007/s12034-011-0187-0

20. Elashmawi, I. (2008). Effect of $\mathrm{LiCl}$ filler on the structure and morphology of PVDF films. Mater. Chem. Phys. 107, 96-100. DOI: 10.1016/j.matchemphys.2007.06.045.

21. Gao, K., Hu, X., Dai, C. \& Yi, T. (2006). Crystal structures of electrospun PVDF membranes and its separator application for rechargeable lithium metal cells. Mater. Sci. Eng. B 131, 100-105. DOI: 10.1016/j.mseb.2006.03.035.

22. Rana, D.S., Chaturvedi, D. \& Quamara, J. (2009). Morphology, crystalline structure, and chemical properties of 100 $\mathrm{MeV}$ Ag-ion beam irradiated polyvinylidene fluoride (PVDF) thin film. J. Optoelectron. Adv. M. 11, 705-712.

23. Ozkazanc, E., Guney, H.Y., Guner, S. \& Abaci, U. (2010). Morphological and dielectric properties of barium chloride-filled poly (vinylidene fluoride) films. Polym. Compos. 31, 1782-1789. DOI: 10.1002/pc.20970.

24. Sajkiewicz, P. (1999). Crystallization behaviour of poly (vinylidene fluoride). Eur. Polym. J. 35, 1581-1590. DOI: 10.1016/ S0014-3057(98)00242-0.

25. Tieyuan, F., Zhishen, M., Ping, H., Yuchen, Q., Shuyun, W. \& Donglin, C. (1986). Study on factors affecting room temperature transition of polytetrafluoroethylene. Chin. J. Polym. Sci. (CJPS) 4, 170-179.

26. Heidarian, J. \& Hassan, A. (2014). Microstructural and thermal properties of fluoroelastomer/carbon nanotube composites. Compos. Part B-Eng. 58, 166-174. DOI: http://dx.doi. org/10.1016/j.compositesb.2013.10.054

27. Heidarian, J., Hassan, A. \& Normasmira, A.R. (2015). Improving the thermal properties of fluoroelastomer (Viton GF-600S) using acidic surface modified carbon nanotube. Polímeros 25(4), 392-401. DOI: 10.1080/09276440.2016.1127668.

28. Heidarian, J. \& Hassan, A. (2015). Improving thermal properties of fluoroelastomer using carbon nanotubes in presence of air and under nitrogen flow. Asian J. Chem. 27, 1235. DOI: http://dx.doi.org/10.14233/ajchem.2015.17200 